\title{
Modeling of mimo less mode division multiplexed systems
}

\author{
Grüner-Nielsen, Lars; Mariam Mathew, Neethu; Lillieholm, Mads; Galili, Michael; Rottwitt, Karsten
}

Published in:

IEEE Photonics Technology Letters

Link to article, DOI:

10.1109/LPT.2020.3016719

Publication date:

2020

Document Version

Peer reviewed version

Link back to DTU Orbit

Citation (APA):

Grüner-Nielsen, L., Mariam Mathew, N., Lillieholm, M., Galili, M., \& Rottwitt, K. (2020). Modeling of mimo less mode division multiplexed systems. IEEE Photonics Technology Letters, 32(18), 1191 - 1194. [9167271]. https://doi.org/10.1109/LPT.2020.3016719

\section{General rights}

Copyright and moral rights for the publications made accessible in the public portal are retained by the authors and/or other copyright owners and it is a condition of accessing publications that users recognise and abide by the legal requirements associated with these rights.

- Users may download and print one copy of any publication from the public portal for the purpose of private study or research.

- You may not further distribute the material or use it for any profit-making activity or commercial gain

- You may freely distribute the URL identifying the publication in the public portal 


\title{
Modeling of MIMO less Mode Division Multiplexed Systems
}

\author{
Lars Grüner-Nielsen, Member, IEEE, Neethu Mariam Mathew, Mads Lillieholm, Michael Galili, \\ and Karsten Rottwitt
}

\begin{abstract}
A transmission model for a mode group division multiplexing system is presented. The model is used to model a two mode group system with either $10 \mathrm{Gbit} / \mathrm{s} \mathrm{NRZ}$ modulation or 25 Gbit/s PAM4 modulation. Influence of wavelength separation between the channels, detector bandwidth and component crosstalk is examined.
\end{abstract}

Index Terms-Space division multiplexing, crosstalk, interference

\section{INTRODUCTION}

$\mathbf{M}$ ODE division multiplexing (MDM) has been extensively researched for now almost 10 years. Impressive results in both reach and number of channels have been obtained using MIMO-DSP. However, MIMO less systems for shorter distances is of interest too, for example for use in data center communications. For data center applications MDM might pose advantages over CWDM systems such as, use of simpler lasers with no wavelength stabilization, and less impact from dispersion as all channels can be at a wavelength close the the zero dispersion wavelength of the fiber.

For MIMO less MDM, it is required to use special fibers with no degenerate modes (except for the polarization degeneracy) such as fibers supporting orbital angular momentum [1], or elliptical core fibers [2]. The focus of this paper will be MIMO less mode group division multiplexing (MGDM), where each mode group supports a transmission channel. This requires use of demultiplexers, which detects the whole mode group. This has been demonstrated using demultiplexers based on multiplane light converters [3], and couplers [4]. Alternatively, each degenerate mode can be detected and their power added either in the optical domain [5] or in the electrical domain [6].

It is important to understand the requirements for the components of a MIMO less MGDM system, especially, the tolerable amount of crosstalk. This can be difficult to do experimentally due to a lot of variables. Therefore, in this paper, we will use a theoretical model for a system supporting the two mode groups $\mathrm{LP}_{01}$ and $\mathrm{LP}_{11}$. The model will be used to analyze the system and find the crosstalk requirements for the mode multiplexers and splices. Only relative short reach systems with lengths limited to tens of kilometers will be

Manuscript received May 26, 2020; revised July , 2020. This work was supported by Innovation Fund Denmark in the project: 8057-00059B, INCOM.

L. Grüner-Nielsen, N. M. Mathew, M. Lillieholm, Michael Galili, and K. Rottwitt are with DTU Fotonik, Technical University of Denmark, Ørsteds Plads, Building 343, 2800 Kgs. Lyngby, Denmark

L. Grüner-Nielsen is also with Danish Optical Fiber Innovation, Åvendingen 22A, 2700 Brønshøj, Denmark e-mail: lars@dofi.dk. considered. Therefore crosstalk in the transmission fiber, DGD within the mode group, and all nonlinear effects are neglected.

\section{MODEL}

The system modeled is shown in Fig. 1a. The back to back case is modeled as shown in Fig. 1b. A linear propagation model of phase and amplitude is used. The field is normalized to the power and characterized by a vector:

$$
\overrightarrow{\boldsymbol{E}}=\left(\begin{array}{l}
\sqrt{P_{01}} e^{-i \varphi_{01}} \\
\sqrt{P_{11}} e^{-i \varphi_{11}}
\end{array}\right),
$$

where $P_{01}$ and $\varphi_{01}$ are the power and phase for $\mathrm{LP}_{01}$ and equivalent for $\mathrm{LP}_{11}$. Then, each component: Input multiplexer (mux), propagation in the two mode fiber (TMF), splice and output mux are modeled by a transfer matrix. For example, the splice is modeled as:

$$
\overrightarrow{\boldsymbol{E}}_{\text {out }}=\left(\begin{array}{ll}
\sqrt{\frac{1-x t_{s 01}}{\alpha_{s 01}}} & \sqrt{\frac{x t_{s 11}}{\alpha_{s 11}}} \\
\sqrt{\frac{x t_{s 01}}{\alpha_{s 01}}} & \sqrt{\frac{1-x t_{s 11}}{\alpha_{s 11}}}
\end{array}\right) \overrightarrow{\boldsymbol{E}}_{\boldsymbol{i n}}
$$

where $\alpha_{s 01}$ and $\alpha_{s 11}$ is the splice loss for $\mathrm{LP}_{01}$ and $\mathrm{LP}_{11}$ and $x t_{s 01}$ and $x t_{s 11}$ the crosstalks; all in linear units. Similarly, neglecting distributed crosstalk in the fiber, the propagation in the two mode fiber is modeled as

$$
\overrightarrow{\boldsymbol{E}}_{\text {out }}=\left(\begin{array}{l}
e^{-i \beta_{01} z} \\
e^{-i \beta_{11} z}
\end{array}\right) \overrightarrow{\boldsymbol{E}}_{\boldsymbol{i n}}
$$

where $z$ is the distance travelled and the propagation constants $(\beta)$ are found as function of wavelength $\lambda$ from:

$$
\begin{array}{r}
\beta_{01}=\beta_{01}\left(\lambda_{0}\right)-\Delta \beta / 2 \\
\beta_{11}=\beta_{11}\left(\lambda_{0}\right)+\Delta \beta / 2 \\
\Delta \beta=\frac{2 \pi c D G D\left(\lambda-\lambda_{0}\right)}{\lambda_{0}^{2}},
\end{array}
$$

where $\lambda_{0}$ is the reference wavelength, $c$ the speed of light in vacuum, and $D G D$ is the length normalized differential group delay between $\mathrm{LP}_{01}$ and $\mathrm{LP}_{11}$. The propagation is the only wavelength dependent element in the model.

The fields out of the lasers after modulation is modeled as:

$$
\overrightarrow{\boldsymbol{E}}_{\boldsymbol{i n}}=\left(\begin{array}{c}
\sqrt{P_{01}(t)} e^{-i\left(\frac{\omega_{B} t}{2}+\varphi_{01}(t)\right)} \\
\sqrt{P_{11}(t)} e^{-i\left(-\frac{\omega_{B} t}{2}+\varphi_{11}(t)\right)}
\end{array}\right),
$$

where $t$ is the time, $P_{01}(t)$ and $P_{11}(t)$ are the powers after modulation, and $\omega_{B}$ is the beat frequency between the two lasers:

$$
\omega_{B}=\frac{2 \pi c\left(\lambda_{L P 11}-\lambda_{L P 01}\right)}{\lambda_{L P 11} \lambda_{L P 01}}
$$




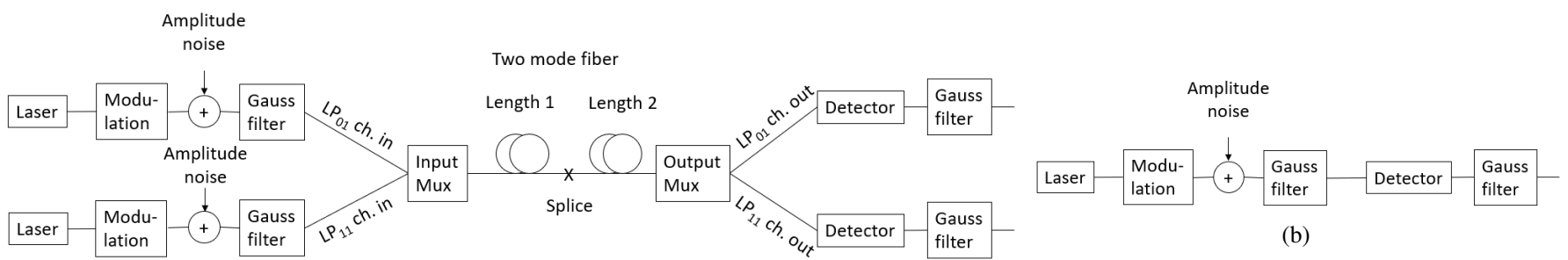

(a)

Fig. 1. (a) Layout of the modeled system. (b) Model for the back to back case.

where $\lambda_{L P 01}$ and $\lambda_{L P 11}$ are the wavelength of the $L_{01}$ and $\mathrm{LP}_{11}$ channels. The phase noise of the two lasers is modeled as a Wiener process [7]:

$$
\begin{gathered}
\varphi_{i}=\varphi_{i-1}+\Delta_{\varphi} w_{i} \\
\Delta_{\varphi}=\sqrt{2 \pi f_{F W H M, \text { laser }} T_{s}}
\end{gathered}
$$

Here, $i$ is the sample number in the simulation, $w_{i}$ is a series or independent random numbers with Gaussian distribution with zero mean and a variance of one, $f_{F W H M}$,laser is the full width half maximum linewidth of the laser, and $T_{s}$ is the time between two samples in the simulation. The amplitude noise is modeled by for each sample in the simulation adding a random number with Gaussian distribution and zero mean. The variance is adjusted to get a reasonable back to back $Q$.

The Gaussian filters used to emulate the modulation bandwidth and the detector bandwidth are both first order Gaussian filters. Typical parameters used for the simulations are summarized in Tab. I. The mux parameters are typical for photonic lantern mode multiplexers developed in our group [6], [8].

The model has been validated by comparing modeled loss versus wavelength with measurements of connected photonic lanterns and a good agreement was found.

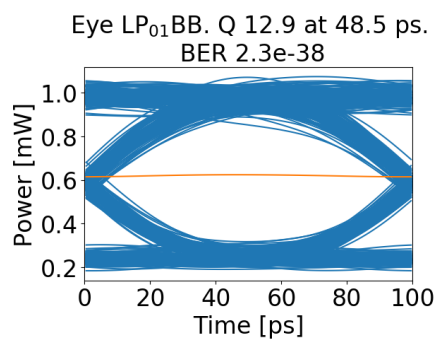

(a) $\mathrm{BB}$

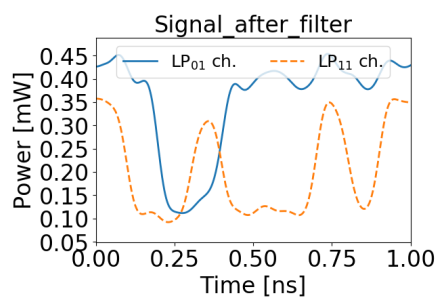

(c)

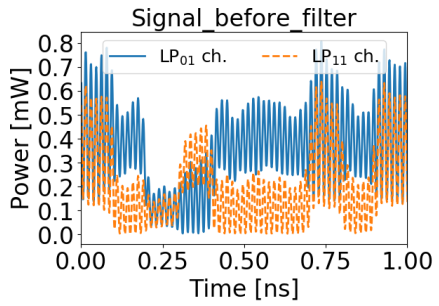

(b)

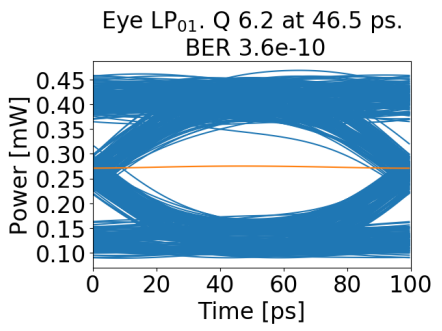

(d) Out
Fig. 2. Results for $10 \mathrm{Gbit} / \mathrm{s}$ NRZ modulation using the parameters of Tab I. (a) Back to back eye for the $\mathrm{LP}_{01}$ channel. The orange line shows the decision threshold. (b) Detector signals before Gauss filtering. (c) Detector signals after Gauss filtering. (d) Output eye for the $\mathrm{LP}_{01}$ channel.
TABLE I

\begin{tabular}{|c|c|c|}
\hline No of bits in simulation & & 500 \\
\hline No of samples per bit & & 100 \\
\hline Modulation frequency & Gbit/s & 10 \\
\hline Modulation extinction ratio & $\mathrm{dB}$ & 7 \\
\hline Modulator $3 \mathrm{~dB}$ bandwidth & $\mathrm{GHz}$ & 20 \\
\hline Laser linewidth & $\mathrm{MHz}$ & 1 \\
\hline Wavelength $\mathrm{LP}_{01}$ channel & $\mathrm{nm}$ & 1551 \\
\hline Wavelength $\mathrm{LP}_{11}$ channel & $\mathrm{nm}$ & 1551.5 \\
\hline Power $\mathrm{LP}_{01}$ channel & $\mathrm{dBm}$ & 0 \\
\hline Power $\mathrm{LP}_{11}$ channel & $\mathrm{dBm}$ & 2 \\
\hline Detector $3 \mathrm{~dB}$ bandwidth & $\mathrm{GHz}$ & 10 \\
\hline Input mux loss $\mathrm{LP}_{01}$ channel & $\mathrm{dB}$ & 1 \\
\hline Input mux loss $\mathrm{LP}_{11}$ channel & $\mathrm{dB}$ & 3 \\
\hline Input mux crosstalk $\mathrm{LP}_{01}$ channel & $\mathrm{dB}$ & -15 \\
\hline Input mux crosstalk $\mathrm{LP}_{11}$ channel & $\mathrm{dB}$ & -15 \\
\hline Length $1\left(L_{1}\right)$ & $\mathrm{m}$ & 6 \\
\hline Length $2\left(L_{2}\right)$ & $\mathrm{m}$ & 4 \\
\hline DGD two mode fiber $(1550 \mathrm{~nm})$ & $\mathrm{ps} / \mathrm{m}$ & 2.1 \\
\hline$\beta_{01}(1550 \mathrm{~nm})$ & $\mu m^{-1}$ & 5.870 \\
\hline$\beta_{11}(1550 \mathrm{~nm})$ & $\mu m^{-1}$ & 5.864 \\
\hline Splice loss $\mathrm{LP}_{01}$ & $\mathrm{~dB}$ & 0.04 \\
\hline Splice loss $\mathrm{LP}_{11}$ & $\mathrm{~dB}$ & 0.04 \\
\hline Splice crosstalk LP 01 & $\mathrm{~dB}$ & -25 \\
\hline Splice crosstalk LP 11 & $\mathrm{~dB}$ & -25 \\
\hline Output mux loss $\mathrm{LP}_{01}$ channel & $\mathrm{dB}$ & 3 \\
\hline Output mux loss $\mathrm{LP}_{11}$ channel & $\mathrm{dB}$ & 4 \\
\hline Output mux crosstalk LP $_{01}$ channel & $\mathrm{dB}$ & -10 \\
\hline Output mux crosstalk LP 11 channel & $\mathrm{dB}$ & -10 \\
\hline
\end{tabular}

PARAMETERS USED FOR SIMULATION.

\section{RESUlts 10 GBIT/S NRZ MODULATION}

Typical simulation results for $10 \mathrm{Gbit} / \mathrm{s}$ NRZ modulation, using the values of Tab. I, are shown in Fig. 2. The $Q$ is calculated from the averages and standard deviations of the zeros and ones [9] and the bit error rate (BER) is calculated from the $Q$, assuming Gaussian distributions of the zeros and ones [9]. This BER should be taken only as an indicative value, since in the presence of crosstalk, the distributions might not be Gaussian as well as the number of bits in the calculations is chosen only to get reliable $Q$ values. The beat noise with frequency given by Eq. (8) is clearly seen on the signals before filtering (Fig. 2b). However, as observed in Fig. 2c, the Gaussian filter, emulating the detector bandwidth, efficiently suppresses this beating. Therefore, an open eye after transmission is obtained as shown in Fig. 2d with a calculated $Q$ of 6.2 at a position in the eye of 48.5 ps and an estimated BER of $4 \cdot 10^{-10}$.

Results for calculated $Q$ versus the wavelength of the $\mathrm{LP}_{01}$ channel for different wavelength separation between the $\mathrm{LP}_{01}$ and $\mathrm{LP}_{11}$ channel are shown in Fig. 3. It should be noted 


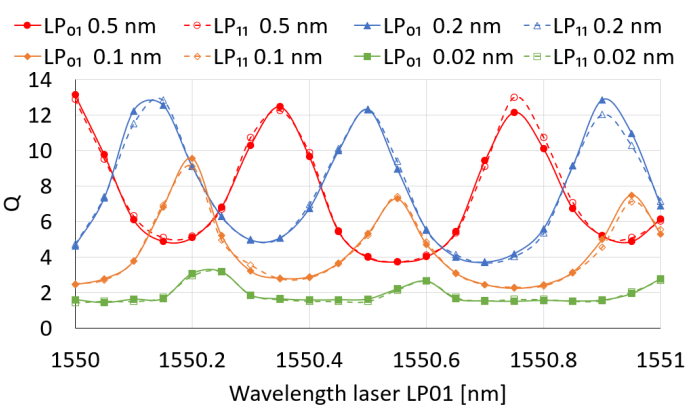

Fig. 3. $\mathrm{Q}$ for the $\mathrm{LP}_{01}$ and $\mathrm{LP}_{11}$ channel vs wavelength of the $\mathrm{LP}_{01}$ channel for different wavelength separations between the $\mathrm{LP}_{01}$ and $\mathrm{LP}_{11}$ channel for $10 \mathrm{Gbit} / \mathrm{s}$ NRZ modulation. Besides the wavelengths, all other parameters are as defined in Tab. I.

that for $Q$ below 2, the eyes are totally closed. That is, it is not possible to model $Q$ below 2 . As the input powers have been adjusted to compensate for the mode depend loss, similar performance is observed for the $\mathrm{LP}_{01}$ and $\mathrm{LP}_{11}$ channels. A clear periodic variation in $Q$ with wavelength is observed in Fig. 3. This can be explained by the interference in the connected few mode system, where the crosstalk varies versus wavelength with a wavelength period $\lambda_{B}$ [10]:

$$
\lambda_{B}=\frac{\lambda^{2}}{D G D \cdot L \cdot c},
$$

where $\lambda$ is the wavelength, $L$ is the length, and $c$ is the speed of light in vacuum. Similar oscillations are seen in modeling and measurements of loss versus wavelength of the system. As the crosstalk in splice is set relatively low compared to the crosstalk of the input and output mux, $L \approx L_{1}+L_{2}$ and thus $\lambda_{B} \approx 0.38 \mathrm{~nm}$, which fits well with the period observed in Fig. 3. To properly resolve this periodic behaviour of $Q$ versus wavelength, relatively short fiber lengths have been used in the simulation. For longer lengths $\lambda_{B}$ can become comparable to or smaller than the modulation bandwidth of the lasers and $Q$ will become more stable versus wavelength. For example for the considered TMF, $\lambda_{B}$ becomes smaller than $0.079 \mathrm{~nm}$ corresponding to $10 \mathrm{GHz}$ for a length larger than $48 \mathrm{~m}$. Still, in practical systems there can easily be relative short lengths between the mode coupling points. For this reason, it is most safe for each trace of Fig. 3 to consider the lowest $Q$ when judging the quality of transmission. It is clearly seen in Fig. 3 that for a wavelength separation between the $\mathrm{LP}_{01}$ and the $\mathrm{LP}_{11}$ channel of $0.1 \mathrm{~nm}(12.5 \mathrm{GHz})$ and below, the performance degrades rapidly. This has also been shown experimentally [6]. When the beat frequency between the two channels get comparable to the detector bandwidth or below, the performance in not only degraded by the crosstalk but also the interference noise from the beating.

To examine the requirements for the crosstalk, simulations are done with the wavelength of the two lasers well separated and with the wavelengths almost equal. The results are shown in Fig. 4. Here, calculated $Q$ is shown as function of the wavelength of the $\mathrm{LP}_{01}$ channel for different crosstalk levels of the components for a wavelength separation of $0.5 \mathrm{~nm}$ in Fig. 4a and $0.02 \mathrm{~nm}$ in Fig. 4b. In these simulations

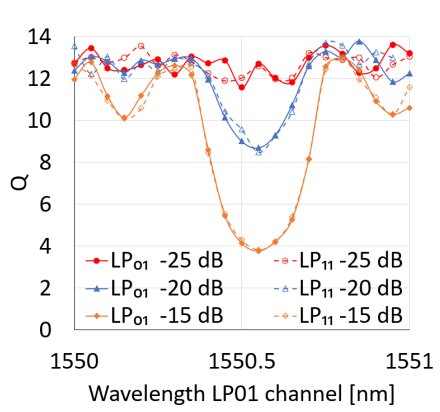

(a) $0.5 \mathrm{~nm}$ wavelength spacing

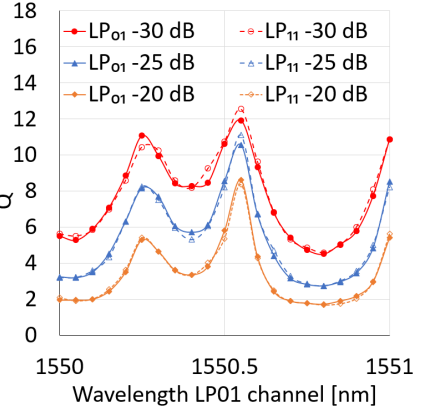

(b) $0.02 \mathrm{~nm}$ wavelength spacing
Fig. 4. $\mathrm{Q}$ for the $\mathrm{LP}_{01}$ and $\mathrm{LP}_{11}$ channel vs wavelength of the $\mathrm{LP}_{01}$ channel for different crosstalk levels. The wavelength separations between the $\mathrm{LP}_{01}$ and $\mathrm{LP}_{11}$ channel are (a) $0.5 \mathrm{~nm}$ (b) $0.02 \mathrm{~nm}$.

the crosstalk for all components: input and output mux and splice are assumed to be the same. Apart from crosstalk and channel wavelengths, all other parameters are still as defined in Tab. I. It is observed that for a channel separation of 0.5 $\mathrm{nm}$ a crosstalk level below $-20 \mathrm{~dB}$ is enough to ensure a $Q>8$ corresponding to $B E R<6 \cdot 10^{-16}$, while for the small wavelength separation of $0.02 \mathrm{~nm}$ a crosstalk below $-30 \mathrm{~dB}$ is required to obtain just $Q>4$ corresponding to $B E R<3 \cdot 10^{-5}$. For a wavelength separation of $0.5 \mathrm{~nm}$ a $Q>4$ can be obtained with a crosstalk values below $15 \mathrm{~dB}$ for all components or as observed in Fig. 3 with the experimentally demonstrated values of Tab. I.

The influence of detector bandwidth has been examined as well. $Q$ versus the detector bandwidth is shown i Fig. 5 for three different wavelengths of the $\mathrm{LP}_{11}$ channel and the back to back case. Apart from the detector bandwidth and the wavelengths of the $\mathrm{LP}_{11}$ channel all other parameters are as in Tab. I. For most cases, it is as expected seen that the optimum is a detector bandwidth equal to the modulation rate. Furthermore, it is noticed that for the smaller wavelength spacing $Q$ gets much more degraded if the detector bandwidth get too large. This is because the interference between the channels is not sufficiently suppressed. For the very small wavelength spacing of $0.1 \mathrm{~nm}(12.5 \mathrm{GHz})$, it is even noticed that optimum detection bandwidth is lower than the modulation rate.

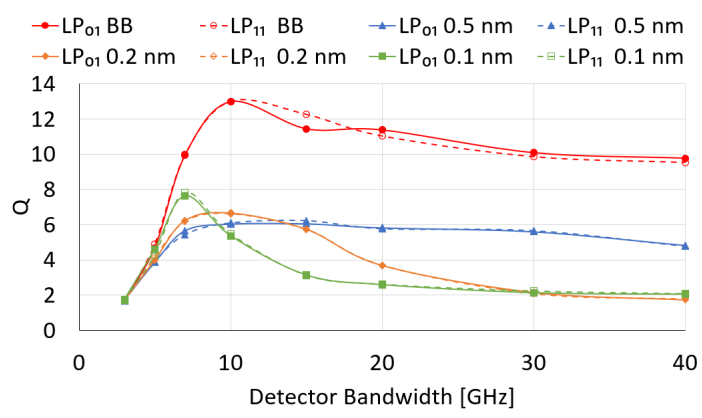

Fig. 5. Q for the $\mathrm{LP}_{01}$ and $\mathrm{LP}_{11}$ channel vs detector bandwidth for the back to back case and after transmission for different wavelength separations between the $\mathrm{LP}_{01}$ and $\mathrm{LP}_{11}$ channel for $10 \mathrm{Gbit} / \mathrm{s} \mathrm{NRZ}$ modulation. 


\section{RESUlTS 25 GBit/S PAM4 MODULATION}

So far, $10 \mathrm{Gbit} / \mathrm{s}$ NRZ modulation has been examined. However, current data center network use up to $400 \mathrm{~Gb}$ Ethernet channels, which typically use $25 \mathrm{Gbit} / \mathrm{s}$ PAM4 modulation. This modulation format has therefore been examined too. Example on back to back eye and eye after transmission are shown in Fig. 6. Here compared to Tab. I, the modulation frequency is increased to $25 \mathrm{Gbit} / \mathrm{s}$, the modulator $3 \mathrm{~dB}$ bandwidth to $30 \mathrm{GHz}$, the detector bandwidth to $25 \mathrm{GHz}$. Furthermore, the input mux crosstalks has been decreased to $-20 \mathrm{~dB}$ and the output mux crosstalks to $-15 \mathrm{~dB}$.

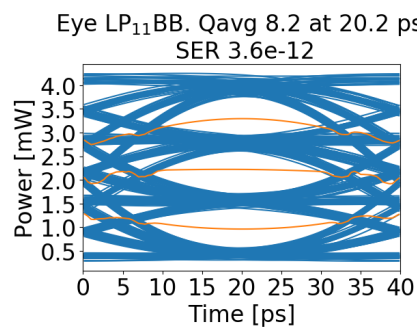

(a) $\mathrm{BB}$

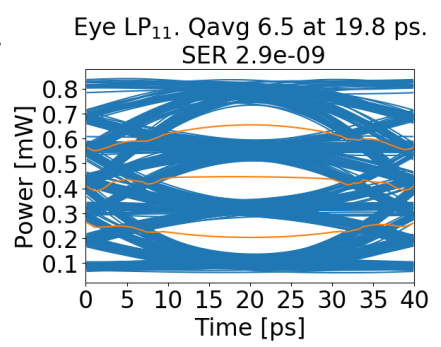

(b) Out
Fig. 6. Calculated eyes for $25 \mathrm{Gbit} / \mathrm{s}$ PAM4 modulation. (a) Back to Back. (b) After transmission. The yellow lines are the decision levels used for the $Q$ calculation

The $Q$ is calculated for the three eyes and from these, the symbol error rate (SER) is calculated [9]. As for the $10 \mathrm{Gbit} / \mathrm{s}$ NRZ modulation, the average of the three $Q$ 's is calculated as a function of the wavelength of the $\mathrm{LP}_{01}$ channel for different wavelength separation between the $\mathrm{LP}_{01}$ and $\mathrm{LP}_{11}$ channel. The result is shown in Fig. 7a. It is observed that due to the higher detector bandwidth necessary for $25 \mathrm{Gbit} / \mathrm{s}$ modulation, a minimum wavelength separation of $0.5 \mathrm{~nm}$ is now needed to suppress detrimental effects of the interference between the two channels.

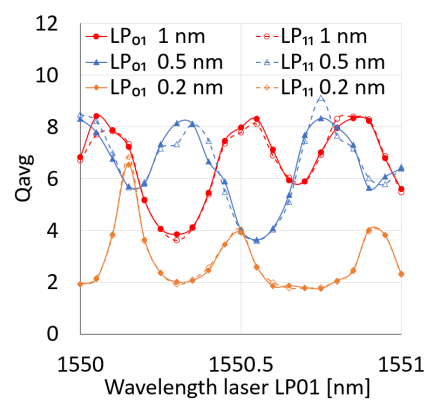

(a)

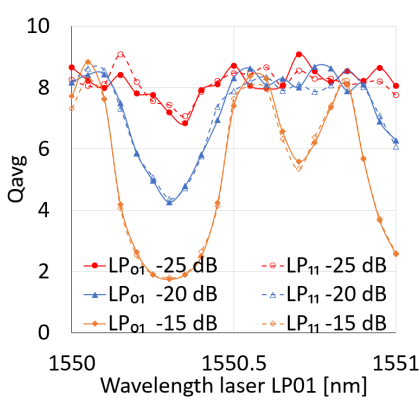

(b)
Fig. 7. $Q$ for the $L P_{01}$ and $L P_{11}$ channel vs wavelength of the $L P_{01}$ channel for $25 \mathrm{Gbit} / \mathrm{s}$ PAM4 modulation. (a) for different wavelength separations between the $\mathrm{LP}_{01}$ and $\mathrm{LP}_{11}$ channel. (b) For different crosstalk levels and a wavelength separation of $0.5 \mathrm{~nm}$

Finally, the requirement for component crosstalk is examined. $Q$ versus wavelength of the $\mathrm{LP}_{01}$ channel for a wavelength separation of $0.5 \mathrm{~nm}$ for different component crosstalk levels is shown in Fig. 7b. As in the similar calculation in Sec. III for the NRZ case, the crosstalk levels are set equal for all components. It is observed that to get an average $Q$ above 4.3 corresponding to $S E R<2 \cdot 10^{-5}$ a crosstalk level below -20 is needed. Where crosstalk below $-15 \mathrm{~dB}$ was enough for similar performance in the $10 \mathrm{Gbit} / \mathrm{s}$ NRZ case.

\section{CONCLUSIONS}

Using a linear propagation model, the performance of, a two-mode, mode group division multiplexing system is examined. Due to the interference effect, the transmission performance varies with wavelength. Two effects degrade the system performance namely, crosstalk and interference between the modes (also know as modal noise). The latter effect can be avoided by using a proper wavelength spacing between the channels. The requirements for crosstalk become much more severe when the wavelength of the two channels are close compared to a wider wavelength spacing. For 10 Gbit/s NRZ modulation, the crosstalks of mode mux, de-mux and splices should be lower than $-15 \mathrm{~dB}$ to secure a bit error rate $B E R<3 \cdot 10^{-5}$, while for $25 \mathrm{Gbit} / \mathrm{s}$ PAM4 modulation, the crosstalks should be below $-20 \mathrm{~dB}$ to get a symbol error rate $S E R<2 \cdot 10^{-5}$. A detector bandwidth equal to the modulation frequency is optimum and are especially important when the wavelength of the two channels are close.

\section{REFERENCES}

[1] K. Ingerslev, P. Gregg, M. Galili, F. D. Ros, H. Hu, F. Bao, M. A. U. Castaneda, P. Kristensen, A. Rubano, L. Marrucci, K. Rottwitt, T. Morioka, S. Ramachandran, and L. K. Oxenløwe, "12 mode, wdm, mimofree orbital angular momentum transmission," Opt. Express, vol. 26, pp. 20225-20232, Aug 2018.

[2] E. Ip, G. Milione, M.-J. Li, N. Cvijetic, K. Kanonakis, J. Stone, G. Peng, X. Prieto, C. Montero, V. Moreno, and J. L. nares, "Sdm transmission of real-time $10 \mathrm{gbe}$ traffic using commercial sfp + transceivers over $0.5 \mathrm{~km}$ elliptical-core few-mode fiber," Opt. Express, vol. 23, pp. 17120-17126, Jun 2015.

[3] K. Benyahya, C. Simonneau, A. Ghazisaeidi, N. Barré, P. Jian, J.-F. Morizur, G. Labroille, M. Bigot, P. Sillard, J. G. Provost, H. Debrégeas, J. Renaudier, and G. Charlet, "Multiterabit transmission over om2 multimode fiber with wavelength and mode group multiplexing and direct detection," J. Lightwave Technol., vol. 36, pp. 355-360, Jan 2018.

[4] Y. Gao, J. Cui, D. Ge, J. Jia, C. Du, C. Xia, Y. Liu, Z. Li, Y. He, Z. Chen, J. Li, and G. Li, "A degenerate-mode-selective coupler for stable dspfree mdm transmission," J. Lightwave Technol., vol. 37, pp. 4410-4420, Sep 2019.

[5] H. Liu, H. Wen, J. C. A. Zacarias, J. E. Antonio-Lopez, N. Wang, P. Sillard, R. Amezcua-Correa, and G. Li, "Demonstration of stable $3 \times 10 \mathrm{gb} / \mathrm{s}$ mode group-multiplexed transmission over a $20 \mathrm{~km}$ few-mode fiber," in Optical Fiber Communication Conference, p. W4J.2, Optical Society of America, 2018.

[6] N. M. Mathew, L. Grüner-Nielsen, M. Galili, M. Lillieholm, and K. Rottwitt, "Cross talk and interference in mimo less few mode transmission systems," in Conference on Lasers and Electro-Optics, p. JW2E.24, Optical Society of America, 2020.

[7] M. P. Yankov, T. Fehenberger, L. Barletta, and N. Hanik, "Lowcomplexity tracking of laser and nonlinear phase noise in wdm optical fiber systems," Journal of Lightwave Technology, vol. 33, no. 23, pp. 4975-4984, 2015.

[8] N. M. Mathew, J. B. Christensen, L. Grüner-Nielsen, M. Galili, and K. Rottwitt, "Air-cladded mode-group selective photonic lanterns for mode-division multiplexing," Opt. Express, vol. 27, pp. 13329-13343, Apr 2019.

[9] F. Cavaliere and A. D'Errico, Photonics Applications for Radio Systems and Networks. Norwood, MA: Arctech House, 2019.

[10] L. Grüner-Nielsen, N. M. Mathew, and K. Rottwitt, "Invited paper: Characterization of few mode fibers and devices," Optical Fiber Technology, vol. 52, p. 101972, 2019. 